\title{
Effects of probiotics and prebiotics in ulcerative colitis
}

\author{
Hijova E, Soltesova A \\ Institute of Experimental Medicine, Faculty of Medicine, Safarikiensis University, Kosice, Slovakia. \\ hijova@pobox.sk
}

\begin{abstract}
Objectives: Inflammatory bowel diseases (IBD) are caused by the failure of immunoregulatory mechanisms due to external environmental factors in genetically predisposed individuals. Probiotics and prebiotics could be used in prevention and therapy of many disorders of gastrointestinal tract including ulcerative colitis. Probiotics are living microorganisms with good tolerability and minimal risk, which confer a health benefit for the host when administered in adequate amounts. Their effect is closely related to maintaining the natural function of the intestinal flora. In this respect, they are indispensable prebiotics to protect or reduce the incidence of inflammatory lesions in diseases of the digestive tract.

Conclusion: Ingestion of probiotics and prebiotics may provide some clues in developing a new class of therapeutic agents for the treatment/prevention of IBD and colitis-associated cancer (CAC) in the future (Tab. 2, Ref. 26). Full Text in PDF www.elis.sk.

Key words: ulcerative colitis, nutrition, probiotics, prebiotics.
\end{abstract}

Chronic nonspecific inflammatory bowel diseases (Inflammatory bowel diseases, IBD) are serious medical and socio-economic problems with continuing increase in the incidence and prevalence. The most important nosological units in this group of diseases are Crohn's disease (Morbus Crohn-MC) and ulcerative colitis (Colitis ulcerosa-CU). A high morbidity, significant early and late complications, and decreased quality of life is the reason for seeking new possibilities for the prevention, rational diagnosis and treatment.

\section{Ulcerative colitis - definition, incidence}

Ulcerative colitis (Colitis ulcerosa - CU) is a chronic, nonspecific inflammatory bowel disease characterized by exudative, hemorrhagic - catarrhal and ulcerative changes mainly of rectal mucosa and submucosa with a possible extension on the remaining part of the intestine.

The incidence of $\mathrm{CU}$ is associated with two age peaks. First observed is in the younger middle generation, with a maximum between 20 and 40 years of life. The other is the end of the fifth and the beginning of the sixth decade of life. About $15 \%$ of patients with CU are aged over 60 years. The highest incidence and prevalence of CU is in Israel, Britain and North America. CU incidence in Europe is about 10.0/100 000 in North America from

Institute of Experimental Medicine, Faculty of Medicine, Safarikiensis University, Kosice, Slovakia

Address for correspondence: E. Hijova, MVD, PhD, Institute of Experimental Medicine, Faculty of Medicine, PJ Safarik University, SNP 1, SK-040 11 Kosice, Slovakia.

Phone: +421.55 .6424606 , Fax: +421.55 .6420253$

Acknowledgements: This work was supported by grant VEGA 1/0279/13 and partially by the Agency of the Slovak Ministry of Education for the Structural Funds of the EU, under ITMS: 26220220104 (30\%), ITMS: $26220220152(40 \%)$.
2.2 to $14.3 / 100000$ inhabitants. The prevalence of CU in Europe is 2-243/100 000 inhabitants (the largest is in northern England). In North America, the prevalence is 170/100 000 and in the Czech Republic, it is 10.4-42/100 000. In Slovakia, the expected incidence is $16.8 \mathrm{CU} / 100000$ inhabitants (Gregus, 2006). Ulcerative colitis is not rare even in childhood. At the end of the 2003, there were 134 children diagnosed with CU ( 62 boys, 72 girls) aged $0-18$ years with the average age of manifested CU $11.68 \pm 0.36$ years. $\mathrm{CU}$ incidence in children in Slovakia in this period was 1.63 to 2.12/100 000 inhabitants (Čierna et al, 2008).

The National Cancer Registry of Slovak Republic process long-term data on cancer incidence in the Slovak Republic, statistically analyzes and evaluates the incidence of malignant tumours in the country, creates designs and implements epidemiological studies that indicate not only the current scope, development and distribution of diseases and deaths from malignant tumours, but also suggests their development and possible causes and associated factors (Diba et al, 2006).

The Ministry of Health stated in the Report on the population health in Slovak Republic for the years 2006-2008 the percentage of causes of death of all deaths in the period as follows:

1) Circulatory system diseases, $46.9 \%$ of men, $61.0 \%$ of women,

2) Tumours, $24.6 \%$ of men, $20.3 \%$ of women,

3) External causes, $9.2 \%$ of men, $2.4 \%$ of women,

4) Respiratory diseases, $6.1 \%$ of men, $5.1 \%$ of women,

5) Digestive system diseases, $6.7 \%$ of men, $4.6 \%$ of women.

Men usually die on cancer of the trachea, bronchus and lung (C33, C34), followed by colorectal malignancies (C18 - C21), colon $(\mathrm{C} 18)$ and prostate $(\mathrm{C} 61)$. For women, the highest mortality rate (number of deaths per 100000 women) was malignant tumours of breast (C50), colon (C18), colorectal (C18-C21) and cancer trachea, bronchus and lung (C33, C34). 
Tab. 1. Criteria for use as a probiotic.

1) The organism must be fully identified: genus, species and strain

2) It must be safe for consumption:

- Not pathogenic or carrying antibiotic resistance genes

- Not degrading to intestinal mucosa or conjugating for bile acids

3) It must survival intestinal transit: Acid and bile tolerant

4) It must adhere to mucosal surface and colonize the intestine (at least briefly)

5) It must possess documented health effects:

- Produce antimicrobial substances and antagonize pathogenic bacteria

- At least one phase 2 study documenting benefit

6) It must be stable during processing and storage

The aetiology of ulcerative colitis is not yet understood. Anticipated are synergies of the three main groups of factors:

- Genetic (familial incidence of 15-20\%, 35-50\% monozygote twins),

- Environmental (environmental impacts, bacterial antigens, stress, smoking, hygiene, nutrition),

- Immunology (immune response, mucosal immune system defect).

The interaction of genetic, environmental and immunology factors suggests the current concept of the pathophysiology of inflammatory diseases. In genetically susceptible individuals, abnormal communication between the intestinal microbial flora and mucosal immune system form the basis of the defect, which is accompanied by mucosal inflammatory lesions of the gastrointestinal tract. The course of $\mathrm{CU}$ is characterized by an impact frequency of unpredictable occurrence of relapse (acute inflammation) and remission (inflammation in decline).

Inflammatory bowel disease (IBD) is a group of chronic inflammatory disorders that affect individuals throughout life. Although the aetiology and pathogenesis of IBD are largely unknown, studies with animal models of colitis indicated that dysregulation of host/microbial interactions included that the loss of epithelial and cell barrier function were pre-requisite for the development of IBD. Patients with long-standing IBD have a higher risk of developing colitis-associated cancer (CAC) approximately $8-10$ years after the initial diagnosis as compared to general populations. In addition to genomic instability (genomic instability - chromosomal and microsatellite instability, which is important for the development of colon cancer, however, the process that causes this genomic instability is not completely understood) that underlies the process of tumorigenesis, continuous inflammation in the intestine seems to be a key factor in CAC development since chronic inflammation is associated with an overexpression of proinflammatory cytokines, chemokines, growth factors as well as their receptors, and reactive oxygen species. In particular, oxidative injury, causing widespread DNA damage, leads to the inception of cancer (Kanneganti et al, 2011).

\section{Therapy of CU}

\section{1) Standard (medical) therapy}

Standard therapy of CU used drugs - Aminosalicylates (5-aminosalicylic acid, 5-ASA, mesalazine), together with glucocorticoids are the essential medication. Aminosalicylates are still considered the first-line treatment for mild to moderately severe CU, shown effective in maintaining remission of the disease. 5-ASA preparations are administered in the form of pro-drug (balsalazid, olsalazine), the active ingredient 5-ASA is released from them mainly in the colon. Glucocorticoids - about $34-45 \%$ of patients with CU requires treatment with glucocorticoids. Immunomodulatory treatment is indicated in case of the lack of effect of treatment with glucocorticoids.

\section{2) Surgical therapy}

\section{3) Alternative or adjuvant therapy -- another form of therapy}

A high importance in the long term is the supportive therapy, which focuses on improving the overall health of the patient. For Crohn's disease and ulcerative colitis, there is no single diet, as we know in diabetic and coeliac disease. In essence, the principle of avoiding foods that cause nausea or abdominal pain, which may vary for each patient. The exact mechanism of action of probiotics and prebiotics is unknown, it is assumed that they act through microbiological modifications, inhibiting intestinal pathogens and stabilizing the immunological barriers in the gastrointestinal mucosa, reducing the production of proinflammatory cytokines. The research suggested that probiotics may offer an alternative or adjuvant approach to conventional therapy by altering the intestinal microflora and modulating the host immune system (Fedorak and Madsen, 2004; Rolle, 2000).

Tab. 2. Controlled trials of probiotics for the induction and maintenance of remission in adults with ulcerative colitis.

\begin{tabular}{|c|c|c|c|c|c|}
\hline Author & Number & Treatment & $\begin{array}{c}\text { Duration } \\
\text { study }\end{array}$ & $\begin{array}{l}\text { Study } \\
\text { design }\end{array}$ & Outcomes \\
\hline Rembacken et al (1999) & 116 & E.coli Nissle 1917 versus mesalazine & 12 months & $\mathrm{R}$ & Maintenance remission \\
\hline Venturi et al (1999) & 20 & VSL\#3 & 12 months & & Maintenance remission \\
\hline Ishikawa et al (2003) & 21 & Yakult versus placebo & 12 months & $\mathrm{R}$ & Maintenance remission \\
\hline Kruis et al (2004) & 327 & E. coli Nissle 1917 versus mesalazine & 12 months & $\mathrm{R}$ & Maintenance remission \\
\hline Cui et al (2004) & 30 & Enterococci, Bifidus, Lactobacillus & 8 weeks & $\mathrm{R}$ & Maintenance remission \\
\hline Kato et al (2004) & 20 & B. breve, B. bifidum, L. acidophilus versus placebo & 12 weeks & $\mathrm{R}$ & Improved in clinical activity index \\
\hline Furrie et al (2005) & 18 & B. longum + fructooligosaccharides & 1 month & $\mathrm{R}$ & Improved profile of cytokines \\
\hline Bibiloni et al (2005) & 32 & VSL\# 3 & 6 weeks & $\mathrm{R}$ & Induction remission \\
\hline Zocco et al (2006) & 187 & L.rhamnosus GG versus mesalazine & 12 months & $\mathrm{R}$ & Maintenance remission \\
\hline
\end{tabular}

$\mathrm{R}$ - randomized controlled trial, VSL\# 3 (8 strains - Lactobacillus acidophilus, L. bulgaricus, L. casei, L. plantarum, Streptococcus thermophilus, Bifidobacterium breve, B. Infantis, B. longum), Yakult (3 strains - B. breve, B. bifidum, L. acidophilus) 


\section{Probiotics, prebiotics}

Probiotics are defined as living food supplements or components of bacteria that have been shown beneficial effects on human health (Salminen et al, 1998). A probiotic bacterium is required to fulfil certain criteria (Tab. 1), (Borchers et al, 2009). The categories of probiotics used today include: bacteria such as lactic-acid bacteria (LAB) and Escherichia coli strains (such as E.coli Nissle 1917, which is one of the few examples of non-LAB probiotic), as well as yeast species including most predominantly Saccharomyces boulardii among others. The treatment of CU most commonly used probiotics alone (E. coli Nissle 1917, Lactobacillus salivarius, L. reuteri, L. casei, L. plantarum, L. rhamnosus GG, Bifidobacterium longum, B. infantis, B. animalis, Saccharomyces boulardii), or a combination of probiotics (VSL\#3, Yakult). VSL\#3 is a highly concentrated probiotic cocktail commercially produced containing 8 strains - Lactobacillus acidophilus, L. bulgaricus, L. casei, L. plantarum, Streptococcus thermophilus, Bifidobacterium breve, B. infantis, B. longum. Yakult is a Japanese probiotic drink composed of three strains - B. breve, B. bifidum, L. acidophilus).

The protective effect of probiotics on colon tumours includes suppression of increase in metabolic activity of bacteria forming carcinogenic, mutagenic substances, binding of carcinogens, formation of butyrate and other substances stimulating apoptosis in abnormal cells, immunostimulatory effects - stimulation of humoral and cellular immunity, protective effects of idiopathic intestinal inflammations and inhibition of the conversion of bile acids into secondary and tertiary. Clinical studies investigated the effect of the probiotics in patients with ulcerative colitis in the induction of remission (treatment of acute ulcerative colitis) and in the maintaining of remission or the preventing of relapse. An overview of 10 studies covering totally 861 patients with $\mathrm{CU}$ is summarized in the Table 2. The number of patients in the studies varied from 18 to 327 patients. The duration of study was different from 4 weeks to 1 month ( 1 study), 6 weeks ( 1 study), 8 weeks ( 2 studies), 12 weeks ( 1 study), and more then 12 months ( 5 studies). In one study (116 and 327 patients), the probiotic non-pathogenic E. coli strain Nissle 1917 was administered. This probiotic intervention was equivalent to mesalazine, drug that is considered the gold standard in maintaining remission in patients with CU and the best evidence supporting the use of probiotics in the treatment ofCU. The second largest study (187 patients) used Lactobacillus rhamnosus GG compared with mesalazine and differences were not observed in the relapse rate at 6 and 12 months, but patients with LGG did not relapse for a long time and it was suitable for the maintenance of remission. In the small study (30 patients), patients received BIFICO capsules (Enterococci, Bifidobacteria, Lactobacilli) to maintain remission induced by sulfasalazine. Patients receiving BIFICO demonstrated lower levels of proinflammatory cytokines and nuclear factor kappa $\mathrm{B}(\mathrm{NF}-\mathrm{kB})$ and increased levels of IL-10 compared to patients receiving placebo. At the same study, the relapse in patients with BIFICO was significantly less frequent. Other small (18 patients), double-blind, randomized study used synbiotics compound with prebiotic (Synergy 1) and probiotics (B. longum) to treat patients with active CU. One month later the patients demonstrated an improvement in clinical parameters.
Prebiotics such as lactulose, inulin, psyllium and other oligosaccharides (found in onions, garlic, asparagus, leeks, artichoke, bananas, tomatoes, wheat, oats, soy beans, and other plants) are defined as non-digestible selectively fermented ingredients (food ingredients) that allow specific changes in the composition and/ or activity of microorganisms in the GIT, which have a positive impact on the health of the host (Gibson et al, 2004). Synbiotics are a combination of a prebiotic and a probiotic, such as inulin and Lactobacillus rhamnosus GG or Bifidobacter longum. The positive effect of prebiotics was shown by authors (Guarner, 2007; Hedin et al, 2007; Leenen and Dieleman, 2007; Looijer et al, 2009), and suggested the possibility of the effective use of prebiotics, which were relatively safe, inexpensive, did not require administration of large quantities and were readily available.

In the study on the possibilities of the prevention and treatment of colitis in addition to clinical trials, animal experimental models are important, which could clarify the differences in the responses to probiotic therapy in animals in comparison with humans (Grimoud et al, 2010; Xia et al, 2011). The implementation of new evidence may help to change of sight in probiotics and prebiotics, which they would receive from the edge of the pharmaceutical interest in the mainstream clinical practice.

\section{Conclusion}

We can say that probiotics have generally beneficial effects on gastrointestinal diseases. It is believed that probiotics may act through competitive inhibition of intestinal colonization by pathogens producing endotoxin, improving gut barrier function and reducing production of proinflammatory cytokines. At present, there is no clear answer, which probiotic is the best, because the effect of probiotics is specific for the strain. The trend, however, tends to increase the effectiveness of probiotics, as well as the mutual application of probiotics with the substrates necessary for their growth - prebiotics or other substances of natural origin. Mutual combination of probiotics and prebiotics can maximize their beneficial effects on the organism and reaching the broader synergistic effect, but the provided hypothesis requires further research. Additional scientific efforts should be directed to clarify the mechanism of action and explaining inefficiency in some indications. The outstanding issues in the future are the choice of probiotic strain, respectively combinations of strains, combinations of probiotics and prebiotics, the dose and duration of administration.

\section{References}

1. Bibiloni R, Fedorak RN, Tannock GW, Madsen KI, Gionchetti P, Campieri M, De SC, Sartor RB. VSL\#3 probiotic-mixture induces remission in patients with active ulcerative colitis. Am J Gastroenterol 2005; 100: 1539-1546.

2. Borchers AT, Selmi C, Meyers FJ, Keen CL, Gershwin, ME. Probiotics and imunity. J Gastroenterol 2009; 44: 659-664.

3. Cui HH, Chen CL, Wang JD, Yang YJ, Cun Y, Wu JB, Liu YH, Dan HL, Jian YT, Chen XQ. Effects of probiotic on intestinal mucisa of patients with ulcerative colitis. World J Gastroenterol 2004; 10: 1521-1525. 
4. Čierna I, Szépeová R, Valachová I, Majorová E. Výskyt Crohnovej choroby a ulceróznej kolitídy v detskej populácii na Slovensku. Gastroenterol. Prax 2008; 7: 101-106.

5. Diba ChS, Pleško I, Hlava P (Eds). Cancer incidence in the Slovak Republic. Bratislava; NCZI, 2010.

6. Fedorak RN, Madsen KL. Probiotics and the management of inflammatory bowel disease. Inflamm Bowel Dis 2004; 10: 286-299.

7. Furrie E, Macfarlane S, Kennedy A, Cumming JH, Walsh SV, O'neil DA, Macfarlane GT. Synbiotic therapy (Bifidobacterium longum/Synergy 1) initiates resolution of inflammation in patients with active ulcerative colitis: a randomised controlled pilot trial. Gut 2005; 54: 242-249.

8. Gibson GR, Probert HM, Loo JV, Rastall RA, Roberfoid MB. Dietary modulation of the human colonic microbiota: updating the concept of prebiotics. Nutr Res Rev 2004; 17: 259-275.

9. Guarner F. Prebiotics in inflammatory bowel diseases. Br J Nutr 2007; 98 (Suppl 1): 85-89.

10. Greguš M. Ulcerózna kolitída. 354-368. In: Jurgoš L, Kužela L, Hrušovský Š (Eds). Gastroenterológia. Bratislava; Veda, 2006.

11. Grimoud J, Duran H, de Souza S, Monsan P, Ouarné F, Theodorou $\mathbf{V}$, Roques $\mathbf{C h}$. In vitro screening of probiotics and synbiotics according to anti-inflammatory and anti-proliferative effects. Int J Food Microbiol 2010; 144: 42-50.

12. Hedin C, Whelan K, Lindsay JO. Evidence for the use of probiotics and prebiotics in inflammatory bowel disease: a review of clinical trials. Proc Nutr Soc 2007; 66: 307-315.

13. Ishikawa H, Akedo I, Umesaki Y, Tanaka R, Imaoka A, Otani T. Randomized controlled trial of the effect of bifidobacteria-fermented milk on ulcerative colitis. J Am Coll Nutr 2003; 22: 56-63.

14. Kanneganti M, Mino-Kenuson M, Mizoguchi E. Animal models of colitis-associated carcinogenesis. J Biomed Biotechnol 2011; 2011: ID 342637, 23 pp, doi:10.1155/2011/342637

15. Kato K, Mizuno S, Umesaki Y, Ishii Y, Sugitani M, Imaoka A, Otsuka M, Hasunuma O, Kurihana R, Iwasaki A, Arakawa Y. Randomised placebo-controlled trial assessing the effect of bifidobacteriafermented milk on active ulcerative colitis. Aliment Pharmacol Ther 2004; 20: 1133-1141.
16. Kruis W, Fric P, Pokrotnieks J, Lukas M, Fixa B, Kascak M, Kamm MA, Weismueller J, Beglinger C, Stolte M, Wolff C, Schulze J. Maintaining remission of ulcerative colitis with the probiotic Escherichia coli Nissle 1917 is as effective as with standard mesalazine. Gut 2004; 53: $1617-1623$.

17. Leenen CH, Dieleman LA. Inulin and oligofructose in chronic inflammatory bowel disease. J Nutr 2007; 137 (Suppl 11): 2572S-2575S.

18. Looijer-van Langen MA, Dieleman LA. Prebiotics in chronic intestinal inflammation. Inflamm Bowel Dis 2009; 15: 454-462.

19. Rembacken BJ, Snelling AM, Hawkey PM, Chalmers DM, Axon AT. Non-pathogenic Escherichia coli versus mesalazine for the treatment of ulcerative colitis: a randomised trial. Lancet 1999; 354: 635-639.

20. Report on population health in Slovak Republic for the years 20062008. www.zdravie.sk/sz/content

21. Rolle DR. The role of probiotic cultures in the control of gastrointestinal health. J Nutr 2000; 130: 396S-402S.

22. Salminen $\mathbf{S}$, Ouwehand AC, Isolauri E. Clinical applications of probiotic bacteria. Int Dairy J 1998; 8: 563-572.

23. Tursi A, Brandimarte G, Giorgetti GM, Forti G, Modeo ME, Gigliobianco A. Low-dose balsalazide plus a high-potency probiotic preparation is more effective than balsalazide alone or mesalazine in the treatment of acute mild-to-moderate ulcerative colitis. Med Sci Monit 2004; 10: PI126-PI131.

24. Venturi A, Gionchetti P, Rizzello F, Johansson R, Zucconi E. Brigidi P, Matteuzzi D, Campieri M. Impact on the composition of the faecal flora by a new probiotic preparation: preliminary data on maintenance treatment of patients with ulcerative colitis. Aliment Pharmacol Ther 1999; 13: $1103-1108$.

25. Xia Y, Chen HQ, Zhang M, Jiang YQ, Hang XM, Qin HL. Effect of Lactobacillus plantarum LP-Onlly on the gut flora and colitis in interleukin-10 knockout mice. J Gastroenterol Hepatol 2011; 26: 405-411.

26. Zocco MA, dal Verme LZ, Cremonini F, Piscaglia AC, Nista EC, Candelli M, Novi M, Rigante D, Cazzano IA, Ojetti V, Armuzzi A, Gasbarrini G, Gasbarrini A. Efficacy of Lactobacillus GG in maintaining remission of ulceraive colitis. Aliment Pharmacol Ther 2006; 23: 1567-1574.

Received August 22, 2011. Accepted June 26, 2013. 